\title{
DONALDO SCHÜLER EM TORNO A TRADUÇÃO E O FINNEGANS WAKE
}

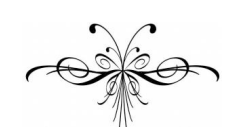

DONALDO SCHÜLER

Donaldo Schüler (1932), professor titular na UFRGS, é reconhecido como um dos principais tradutores brasileiros contemporâneos, dentre cujas traduções destacam-se Finnegans Wake/Finnicius Revém, de James Joyce, Odisséia, de Homero, Antígona, de Sófocles, Banquete, de Platão, e Édipo em Colono, de Sófocles. Com sua tradução de Finnegans Wake, Schüler produziu a primeira tradução completa desta que é tida como a obra mais experimental, intrigante e complexa de James Joyce, publicada pela Editora Ateliê, de São Paulo.

O depoimento a seguir foi concedido por Donaldo Schüler a Marie-Hélène Torres e Mauri Furlan, em 2004, de maneira informal, em seu hotel, durante o IV Encontro Nacional e III Encontro Internacional de Tradutores, em Fortaleza, CE, promovido pela ABRAPT. A conversação foi primeiramente gravada e posteriormente transcrita, admitindo-se então somente pequenas alterações necessárias à apresentação da textualização escrita. Inicialmente, este depoimento fazia parte de um projeto - não realizado - de publicação de relatos de tradutores. Durante a organização deste número temático da revista Scientia Traductionis, tivemos a oportunidade de recuperá-lo e apresentá-lo em um contexto propício.

Mauri Furlan

Novembro de 2010 
$\mathbf{P}$ ode ser que sejamos tradutores sempre. Eu derivo traduzir do latim traducere, que é levar de um lugar para outro, de modo que, se nós contamos um acontecimento, estamos traduzindo porque estamos levando este acontecimento para outro lugar. Traduzimos quando escutamos e reproduzimos o que foi escutado. Eu entendo que o ato de traduzir é um ato de traduzir generalizado; assim, deveríamos inserir aquilo que especificamente se pode traduzir dentro de um processo geral de tradução.

Mas eu não sou um tradutor profissional nem pretendo me profissionalizar em tradução. De modo que quando eu traduzo, traduzo para uma situação específica, e, como tradutor de Finnegans Wake, eu me inspiro na escola do concretismo paulista de Augusto de Campos e Haroldo de Campos. Pensando sobre o processo de renovar o texto e de recontextualizá-lo, eu refleti a partir das proposições que fez o grupo concretista de São Paulo. Para mim, um tradutor deveria reunir diversas qualidades.

Em primeiro lugar a gente deve conhecer a língua e a cultura de origem, e sobretudo conhecer a sua própria cultura. E isto estava muito presente tanto nestas traduções como em outras que eu faço. No meu caso, a fidelidade é muito maior para o ato criativo do que com respeito à literalidade. A literalidade leva necessariamente a uma subordinação do texto traduzido ao texto de origem, enquanto que eu pretendo manter um diálogo entre o texto traduzido e o texto original, sem subordinação e sem uma posição de hegemonia do texto traduzido com respeito ao original. $\mathrm{O}$ texto traduzido é outro texto.

Sem sotaque estrangeiro, texto algum terá o caráter de tradução. O sotaque afeta o movimento da frase, o arranjo das palavras, o choque consonantal e vocálico. Se o tradutor não topa o estranho, não há o que traduzir. Minha preferência é pelo diferente, por duro que o diferente seja. Cômodo é o familiar. Familiar é o que não se move, o que persiste no mesmo lugar. O familiar não admite tradução. Domesticar é tornar o estranho familiar. Na tradução, o familiar provoca estranhamento. Quem lê texto traduzido sabe que tem em casa o que veio de fora. Nasce daí a suspeita da infidelidade. O texto traduzido, por se equilibrar na posição inconfortável da rejeição e da aceitação, não apaga em si os estigmas da infidelidade. Consulto, comparo, faço e refaço. Enquanto traduzo estou inquieto. Encontro por vezes no texto respostas a dúvidas. Traduzir é uma aventura. Nunca se sabe o que vai acontecer. Quem traduz anda em floresta sem mapas, sem veredas. Cada texto tem um comportamento próprio. Você convive com ele, você se tortura com ele, ou você não traduz. Se você não sustenta a luta, o texto o aniquila. Texto fácil de traduzir é ilusão. Em literatura o ar de facilidade costuma ser trabalhosamente produzido. A tradução o habitua a conviver com as artimanhas da fabricação. Textos que conheço bem, quando invento de traduzi-los, descubro neles segredos que me eram inteiramente estranhos. Traduzir é um aprendizado 
lento, compensador. Não falo como tradutor profissional. Traduzo eventualmente, impelido por necessidades didáticas ou por eixgências de minha própria produção. Em tradução não sou nada sistemático.

Mas isto está dentro desta concepção da tradutibilidade ou traduzibilidade universal. Porque não existe discurso hoje, e todo discurso é produzido por um outro discurso. O discurso que proferimos está eivado de citações. Se eu falo da língua portuguesa, eu não sou o primeiro falante da língua portuguesa, isto quer dizer que eu cito toda esta tradição da língua portuguesa. No ato específico de tradução não haveria nem possibilidade diferente de que este texto fosse um texto diferente. Eu pretendo manter um diálogo entre este texto e o texto de origem, assim como em relação a outros textos. Para ser vivo, ele tem que se manter dentro deste processo de diálogo. De sorte que eu aprendo muito com traduções, não pela fidelidade ao texto original, mas precisamente pela infração. A infração me ensina muito, de modo que se esta infração é intencionalmente produzida, ela tem tanta importância como às vezes um comentário sobre o texto. Um texto literário na origem deverá constituir-se como tal no destino. A leitura é o destino do texto literário. A literatura circula da escrita à leitura e da leitura à escrita, dentro da mesma língua ou de uma língua à outra. Não há tradução definitiva. De tempos em tempos, a tradução deverá ser refeita. Refeito, o texto bem traduzido terá ares de novidade, sem perder marcas de outros tempos, de outras culturas. Literatura é diálogo, de texto a texto, de cultura a cultura. No diálogo a literatura se refaz. O texto traduzido provoca o renascimento do texto de origem em outro lugar, em outra cultura. Não se concebe tradução literária sem produção literária. Traduzir é produzir. Quem traduz entra no processo da tradução. Considere-se que o tradutor produz a partir de outro lugar. O outro lugar terá que ressoar neste lugar. Não se entenda a literatura como vinda de um misterioso lugar nas nuvens, concepção mítica, nem brotada de geniais cavernas interiores, concepção romântica. Literatura é ressonância. $\mathrm{Na}$ ressonância, o encontro e a transposição de significantes produz significações. O autor é auctor, fundador. Enquanto fundador, o tradutor refunda o já fundado. Toda fundação literária demanda refundação.

Na minha tradução de Finnegans Wake, usei de estratégias que comprovam essa transcriação, essa transgressão à cultura, à língua. Eu escancaro esta situação desde o princípio. Eu não pretendo escondê-la. Eu coloco, por exemplo, a expressão que aparece na primeira linha de Finnegans Wake, "band of bay". Associo essa baia de Dublin a Bahia, ao estado da Bahia no Brasil. Escrevo Bahia com maiúscula. Quer dizer então que esse próprio ato de consciência "creyssiano", como no meu caso, continua na tradução porque produz um processo de associações. Portanto é um processo vivo. A tradução é como que solicitada pelo texto original. Está no mesmo nível da leitura, que é um tipo de tradução, dentro deste

\footnotetext{
${ }^{1}$ Relativo a Seu Creysson, personagem de Casseta \& Planeta.
} 
processo geral de tradução. Eu me coloco dentro desta situação, digamos então, dialógica. E este ato de criar, efetivamente, se coloca ao nível do ato de criar originário e para criar tem que se entrar dentro do próprio jogo poético da criação.

O Finnegans Wake é uma prosa poética, é um poema. Então eu devo me colocar dentro desta situação poemática de fazer, de um fazer estético. Tanto é assim que a tradução deve ter um laço, um estatuto em que ela se mantém como texto traduzido e que possa ser lido, que possa ser analisado na sua autonomia. Isso acontece, por exemplo, inclusive na tradução de Edgar Allan Poe para o francês, em que o texto traduzido teve uma importância tal que produziu um impacto sobre a literatura francesa. Esta tradução bem feita divulgou Poe para o mundo. Evidentemente, não era um Poe americano, mas um Poe francês. Quer dizer que, este caráter a tradução bem sucedida tem que ter.

Eu traduzi, por exemplo, textos de filosofia, todos os fragmentos de Heráclito, várias tragédias. Também traduzi do alemão textos ainda não publicados que eu uso para meus trabalhos de poesia. Agora, veja bem, eu não considero Joyce um autor que se destaca por natureza da tradição da literatura ocidental. Eu considero Joyce um clássico, um clássico ao nível de Sófocles, ao nível de Dante, ao nível de Shakespeare, efetivamente de caráter inovador, mas Joyce repercute em toda literatura ocidental, e não só na literatura ocidental como também na literatura oriental. Ele repensa e reescreve a literatura precedente. Esta é a marca da sua classicidade. Não descubro em Joyce nenhum processo que não seja usual na literatura. O que existe em Joyce é a exasperação de processos literários.

Antes de Joyce, afirmava já Mallarmé o caso em que a palavra deve ser uma palavra que seja carregada de significações, palavra produzida, que não deve ser uma palavra transcrita da língua falada ou dos dicionários para a literatura, mas que deve ser uma palavra recriada. Essa consciência da recriação já está consciente em Mallarmé. Pois bem, esse processo malarmaico está muito presente também na elaboração joyciana, ele se coloca dentro da tradição da literatura ocidental. Então o que ele requer efetivamente é uma atenção a tudo o que produz a palavra, ele não deixa o leitor descansar, requer uma leitura atenta; e isso é o que se faz, por exemplo, na poesia. Este mesmo comportamento deve se assumir diante do texto de Joyce, principalmente Finnegans Wake.

$\mathrm{Eu}$ penso no leitor como eu-leitor. O tradutor é um leitor. Não pretendo me colocar entre Joyce e os leitores, para manter a autonomia do leitor. Isto quer dizer que a responsabilidade de entender um texto é do leitor. E a literatura contemporânea, a literatura do século XX tira essa hegemonia do autor sobre o leitor. Então o tradutor não deve pretender assumir uma hegemonia sobre o leitor. Facilitar o texto de Joyce seria humilhar o leitor, isto eu não faço!

Gostaria de voltar um pouco sobre o movimento concretista. Eu acompanhei o movimento concretista desde meados dos anos 50 do sé- 
culo passado, quando o movimento concretista eclodiu. Recentemente eu recebi convites de sociedades psicanalíticas de Porto Alegre para realizar seminários de mitologia e literatura, e também de Finnegans Wake. Sabese que Lacan tem muito interesse em James Joyce. Ele, quando jovem, assistia leituras de Ulisses em Paris, e escreveu um seminário, que é o seminário 23 , em que deriva um conceito, um novo conceito psicanalítico, precisamente de Finnegans Wake. Não é um procedimento de Lacan analisar psicanaliticamente Joyce, mas, pelo contrário, aprender um processo e introduzir na psicanálise recursos que se encontram, por exemplo, em Joyce. Então a difusão de Joyce especificamente no Brasil através das sociedades psicanalíticas é um fenômeno fundamental. Há vários estágios desta situação.

Tudo o que eu escrevi sempre foi em função de uma solicitação, porque estava desde o início, quando comecei a escrever, consciente desta responsabilidade social da literatura. Não escrevia pelo prazer de escrever, mas respondendo a uma demanda. Quando se começa a escrever procura-se editoras. Agora, há um momento em que a editora procura quem escreve. E então a gente tem que ser suficientemente sábio diante desta solicitação para não se deixar induzir diante o próprio interesse das editoras. Porque acontece o seguinte: existem editoras que dizem, por exemplo, como a ficção deve ser escrita. Deve ser uma ficção linear, deve ter um vocabulário fácil. Se a gente deixar se seduzir por isso, trai a própria literatura. Estava na expectativa de que isso acontecesse, então telefonei a uma editora que eu já conhecia, a editora Ateliê. Eu perguntei se estava interessada na tradução e o editor respondeu que publicava. Ele não quis nem ver o texto.

Eu dirigia seminários de literatura em sociedades psicanalíticas que solicitavam que eu abordasse Joyce. Evidentemente que para tratar um autor dentro de um ambiente em que não se espera que as pessoas sejam suficientemente versadas em uma língua estrangeira, muito menos uma língua complexa como é a língua de Joyce, tive que começar a trabalhar com traduções de Haroldo de Campos (16 fragmentos). Verificamos que para ter uma idéia mais completa do processo criativo de Joyce, estes 16 fragmentos não eram suficientes. Pensei em aumentar os fragmentos e planejei traduzir tudo. Dividi as 628 páginas do texto original em 628 dias, e resolvi traduzir uma página por dia.

Se traduzir significasse levar [o mesmo] de um lugar para outro, traduzir seria impossível. Porque não se leva [o mesmo] de um lugar para outro. No momento em que se leva de um lugar para outro, o sentido é diferente, porque as associações são diferentes. $\mathrm{O}$ discurso é uma situação viva, então, estamos neste processo de tradução, vamos ao paradoxo. Só existe tradução e tradução é impossível, e então vocês perguntam: como foi possível traduzir Finnegans Wake? Os que trabalham com a tradução sabem disso, traduzir é impossível porque não se pode levar nem dentro 
de uma língua de um lugar para outro muito menos de uma língua para outra.

James Joyce, leitor de Ulisses, cria o Ulisses dublinense, o new point blunt, que tem pelo menos estas características homéricas de ser multifacetário, tão multifacetário que cada capítulo do Ulisses tem um estilo próprio. Se ainda no século XVIII se dizia que o estilo é o homem mesmo, e se eu estou diante de 18 capítulos que são 18 estilos, então se perdeu tanto o estilo como se perdeu o homem. O homem se multiplicou nesta situação toda; enfim, isto pode corresponder até a um sentimento do século XX; este penso, logo existo cartesiano foi abalado tanto pela psicanálise como pelas artes, como pela filosofia, como pela narrativa. Se alguém me diz 'homem', é um significante sem significado; esse significado vai se construindo ao longo da história e eu preciso situá-lo em cada momento da história. Agora, eu, leitor de Homero, eu não tenho efetivamente condições de repetir Homero, este Homero que eu leio, mesmo o que eu leio dentro de uma tradução, que já é uma transposição para uma outra língua; mas mesmo que eu leia em grego, este homem homérico será necessariamente diferente. Então, é possível traduzir? Sim e não, fiquemos no paradoxo. Esta situação tem que ser efetivamente teorizada, enfim, ela deve gerar um comportamento, um comportamento teórico para a tradução do Finnegans Wake. Como eu não sou teórico da tradução, eu não tenho um compromisso com nenhuma teoria da tradução, mas entendo que a teoria da tradução me deve ser dada pelo trabalho que eu traduzo. Quer dizer que, como eu li em Finnegans Wake que traduzir é impossível, eu escancaro esta impossibilidade. Começo por exemplo traduzindo o romance por 'Rola rio', passando por Adão e Eva, passando pela Bahia e assim por diante. Agora esse ‘Rola rio’ não está escrito em Joyce. Em Joyce se lê 'River run'. Deve-se entender efetivamente esse 'River run'. Existe o verbo 'to run' que significa correr, então eu tenho o fluir do rio, mas 'run' em inglês também significa 'runa', que é uma escrita criptográfica originária do alfabeto latino, que surgiu por volta do terceiro século da era cristã, se difundiu na Europa e parece que tem representações em todo território europeu, e se associou um caráter sagrado a essa escrita misteriosa. Esse 'run' é esse mistério que tem a obra de arte, é esse mistério que tem Finnegans Wake. São essas runas pelas quais passa o rio, e passa pelas runas continuamente, quer dizer que então é um fluir através do texto que atravessa todos os textos. E se a tradução em língua portuguesa é pertinente, esse fluir deve passar pelo texto da língua portuguesa, de sorte que a minha fidelidade é a construção do romance e não aos resultados que ela deu na língua inglesa, com posições muito peculiares e com convergências muito peculiares de James Joyce, e que efetivamente não é possível reproduzir. Escancaro a diferença para produzir conscientemente o Finnegans Wake em língua portuguesa, um Finnegans Wake brasileiro. Publicamos o texto numa edição bilíngüe e o leitor que não se satisfaz com essa situação pode viajar na mesma edição para o 
texto em inglês. Nossa preocupação foi também a de criar um diálogo entre o texto traduzido e o texto original.

Como foi possível, como é possível ler Finnegans Wake? Na verdade poderia dizer que todos os textos são ilegíveis. Reproduzir o texto tal qual, isso é impossível. Existe um conto de Borges sobre essa situação, de um individuo que queria reescrever Don Quixote e não conseguiu, porque para reescrever ele teria que usar a língua de Don Quixote, inclusive as vírgulas que ele usou, e se ele fizesse isso, fizesse uma segunda versão igual ao Don Quixote, seria diferente. Diferente por quê? Porque o primeiro é o original, o segundo é cópia. A cópia não pode ser igual ao original. De modo que ninguém copia de ninguém, porque é impossível copiar de alguém. Eu não posso copiar o original porque eu não reproduzo o original. Quer dizer que então não existe cópia, então não existe leitura, ninguém lê ninguém, então ficamos no paradoxo. Todos os textos são ilegíveis e vamos ficar no paradoxo. Todos os textos são legíveis.

Digamos que alguém me apresenta, por hipótese, uma página em polonês. Eu não sei nada de polonês. Eu diria 'esta página é ilegível'. Ilegível por quê? Ilegível para mim. Para mim num determinado momento. Se eu entendesse que a língua polonesa é uma coisa importante para minha cultura, creio que por mais complexa que fosse a língua, dentro de um ou dois anos eu poderia ter alguma competência na língua polonesa. Onde está a ilegibilidade? A ilegibilidade está sempre no leitor. A ilegibilidade não existe nunca no texto. Ficamos no paradoxo, todos os textos são ilegíveis e não existe texto ilegível, porque ninguém é capaz de mostrar a marca da ilegibilidade dentro do próprio texto. Quer dizer, então por que não se lê Finnegans Wake? Ninguém é obrigado a ler Finnegans Wa$k e$. Tem tanta coisa para ler, tem milhões de livros para se ler, por que ler Finnegans Wake? Agora, eu não posso declarar, decretar que Finnegans Wake seja ilegível. À medida que eu vou avançando na leitura de Finnegans Wake, eu descubro que Joyce mistura línguas - mistura mais de 60 línguas -, cria palavras a toda hora - cria mais de 60.000 vocábulos -, quer dizer, se nós nos comunicamos razoavelmente com três a cinco mil vocábulos, ele usa sessenta mil vocábulos [novos]. Esse texto é efetivamente ilegível para um falante de língua inglesa, e dos melhores. No momento que eu reconheci que efetivamente é um texto importante, eu faço esse trabalho de hermenêutica, um trabalho de interpretação, que leva muito tempo, que é vagaroso.

Para traduzir Finnegans Wake tem que traduzir uma página por dia. O romance tem 628 páginas; isso leva de três a quatro anos. Na medida em que eu vou traduzindo eu vou lendo. Pois eu não posso traduzir uma coisa que eu não entendi, que eu não li. Ler Finnegans Wake não é diferente, por exemplo, de ler o Coup de dés de Mallarmé. Finnegans Wake é uma ópera, é um poema, além de ser um romance. Mas um romance que exige ser lido palavra por palavra. Agora, por que isso? Porque os teóricos e já os teóricos daquela época diziam que as palavras poéticas 
deveriam ser tiradas da língua comunicativa e tornadas essenciais. Um texto que eu leio com facilidade não me apresenta absolutamente nada. Por isso eu digo para alguns amigos meus que afirmam que gostam de ler, mas gostam de ler literatura fácil, eu digo 'se vocês não têm tempo a perder então não leiam literatura fácil. Agora, se vocês economizam o seu tempo, vocês têm que ler Finnegans Wake'. Porque ler uma literatura fácil, ler ou não ler, é a mesma coisa que reiterar aquilo que eu já sei. Algumas traduções marcaram época na literatura brasileira. Lembro Odorico Mendes. As traduções de Odorico me iniciaram na leitura de Homero. Fui depois a Carlos Alberto Nunes. Freqüentei traduções em outras línguas. Enquanto isso, ia descobrindo que Homero é diferente de todas as traduções. O grego de Homero nunca me fez esquecer as traduções. Li o poema The Raven de Edgar Allan Poe na tradução de Machado de Assis. Para mim as traduções são visíveis. Apontam-me ângulos que sem elas eu não descobriria. As traduções me encantam, me entusiasmam, me desapontam. Não consigo viver sem elas. Não falo das traduções comerciais. Estas me são inteiramente invisíveis. Interessei-me pelos concretistas. Li, ouvi, convivi com Haroldo de Campos. Temos dele agora a tradução marcante da Ilíada. Ele me ensinou que traduzir é tarefa séria. O movimento concretista arejou a tradução literária no Brasil. Proust foi traduzido por nomes salientes como Carlos Drummond de Andrade, Manuel Bandeira, Mario Quintana, Lucia Miguel Pereira. Tenho Balzac, traduzido por Paulo Rónai. Leio Montaigne, traduzido por Sérgio Millet. Geir Campos me deu Rabelais em português. Paul Valéry me veio na tradução de Augusto de Campos. Freqüento William Carlos Williams na tradução de José Paulo Paes. Vieram os novos, Jaa Torrano e Joaquim Brasil Fontes, entre eles. Leio-os, converso com eles. Descobrimos juntos. Não são poucos os escritores de proa que se dedicaram à tradução.

Modernamente, digamos a partir da Idade Média, o que pôs em evidência a importância da tradução foi o texto sagrado, inclusive o texto, a tradução de Jerônimo da Bíblia, do Antigo Testamento, em hebraico, e do Novo Testamento, em grego. O trabalho de Jerônimo é um trabalho altamente criativo. Jerônimo não teve essa preocupação da literalidade. Porque alguns teóricos fazem uma diferença, por exemplo, entre o texto sagrado e um texto criativo. Essa diferença é uma diferença muito problemática. Jerônimo tentou entrar no espírito da escritura e estava muito atento ao latim falado no quarto século, descrevendo inclusive sua própria tradução, que se chama Vulgata: isso significa traduzir para a língua vulgar. Mas ele transforma esta língua vulgar em uma língua literária. O que ele traduz, o que ele realiza já no quarto século é aquilo que Lutero, por exemplo, realiza na Alemanha. A tradução de Lutero é uma nova vulgata em que ele cria o idioma alemão. Tanto é assim que estabelece uma tradição que vai, por exemplo, até Goethe. O Fausto de Goethe começa citando a tradução de Lutero e discutindo a tradução de Lutero. Joyce pretende fazer isso no século XX. Ele pretende ser uma espécie de escritura 
sagrada do século XX, em âmbito bem maior, em âmbito universal de refazer a língua.

Quanto ao método, não entendo que me distancio fundamentalmente daquilo que fazia Jerônimo. Uma tradução que pretende ser uma tradução literal não se sustenta dentro da língua que a recebe. Essa língua que a recebe estabelece condições ao tradutor ou então ao texto. O texto funciona dentro da língua que a recebe ou não funciona. E Joyce pretende ressacralizar o texto. É um repensar inclusive da sacralidade. Joyce não exclui nada desta situação global do processo. Enfim, o que acontece: antes de ter uma teoria de uma tradução que subordinaria o texto à minha teoria da tradução, eu comecei a fazer uma teoria de tradução a partir do texto. Pode ser que isto seja uma obrigação diante de todos os textos, porque se todos os textos traduzidos são textos novos, eu devo descobrir esta novidade para estabelecer um diálogo com a novidade. Caso contrário, eu mato o texto, inclusive posso matá-lo com a minha teoria de tradução préconcebida. Enfim, é o texto que me impõe um método de tradução. Eu tenho que inventar um método para este texto exclusivamente, que tem características suas próprias. Conscientemente ou não, isto pode acontecer inclusive dentro do ato de criar, mas a sensibilidade para este processo criativo necessariamente há que se ter. De modo que eu não conheço traduções, que efetivamente fossem revolucionárias e significativas, que não tivessem este procedimento de refazer aquilo que está sendo feito em outras condições. Por isso eu não vejo uma diferença essencial entre o tradutor e o leitor. Esse leitor consciente, inteligente, assim como o tradutor, tem que entrar dentro deste trabalho de elaboração. Quando eu faço isso eu já estou traduzindo.

Agora, veja o seguinte: coloco isso dentro de uma posição na literatura brasileira. A literatura brasileira, efetivamente, é uma literatura vigorosa, que antecede inclusive a literatura norte-americana. Quando no século XVII a literatura norte-americana era piedosa e de nenhum valor, nós tínhamos no Brasil Gregório de Matos, tínhamos o Padre Vieira, que é um dos grandes prosadores de língua portuguesa e um dos grandes intelectuais de todos os tempos, isto para o leitor de hoje. Os sermões centrais de Vieira são peças literárias da mais alta categoria. Nós temos uma tradição que vem desde Gregório de Matos, Vieira, os arcadismos mineiros, Machado de Assis, Oswald de Andrade, Mário de Andrade - que para mim foi muito importante -, Guimarães Rosa, João Cabral de Melo Neto... Temos uma posição crítica brasileira que coloca o Brasil numa posição singular, numa posição favorável dentro da literatura universal e esta resposta brasileira foi feita antes pela imprensa. A minha primeira surpresa [com relação a Finnegans Wake] foi que uma obra, que no exterior sempre está ligada a pequenos grupos, tenha uma repercussão na imprensa como efetivamente teve, tanto nos periódicos do Sul, como no Rio de Janeiro, como em São Paulo, como no Nordeste, como até em Mato Grosso, como em toda parte. Isto quer dizer que foi uma atenção generalizada 
no Brasil. Então deve se examinar esta situação, dentro deste fenômeno, de uma posição crítica e de uma exigência da literatura brasileira que coloca a cultura e a literatura brasileira em uma posição favorável. Agora, quando falo sobre Joyce, inclusive aqui neste congresso ${ }^{2}$, falo para salas repletas de jovens e jovens que me saúdam entusiasmados. Portanto nós temos um dever, inclusive por esta juventude. $\mathrm{O}$ que quero dizer é que se às vezes nós depreciamos a juventude, depreciamos o leitor brasileiro e não estamos suficientemente atentos ao que se passa no Brasil.

O que mais deveríamos traduzir no Brasil? Nós estamos numa posição boa com respeito a alguns fenômenos da literatura universal. Veja, as obras de Borges foram totalmente traduzidas, apareceram traduções da obra completa. Os Cantos de Ezra Pound foram todos traduzidos por José Lino Grünewald. Foi traduzido tudo, inclusive houve uma modificação nos últimos anos no Brasil com respeito à tradução, e evidentemente os irmãos Campos tiveram muita importância nisso. Agora, pensando em alguns nomes do passado, eu acho que um poeta como Trakl - eu traduzi alguns poemas dele -, Trakl como simbolista do início do século é muito importante. Se pensamos nesta vanguarda, eu acho que Kafka deveria ser melhor traduzido porque quando Kafka começou a ser difundido houve muita sede de Kafka, e fizeram-se traduções apressadas. Eu acho que Kafka deveria ser traduzido com a mesma atenção, e em traduções diretas.

Dentro deste processo, eu traduzo sempre para os meus grupos de estudos, e são muitos que se formam voluntariamente. Eu traduzo os textos porque isto me dá uma responsabilidade maior. Como eu não faço diferença entre a leitura e a tradução, me sinto obrigado a traduzir para entender bem. Porque a tradução dá a obrigação de refletir sobre tudo, então me habituei a este processo.

Mas também quando posso leio textos de psicanálise no original. Freud, por exemplo, eu leio em alemão; Lacan leio em francês. Lacan é muito complicado, inclusive do ponto de vista lingüístico. Uma sugestão que já tinha dado Haroldo de Campos e que acho que deveria ser levada em consideração é que estes textos deveriam ser traduzidos conjuntamente por um psicanalista que conhecesse bem o texto a ser traduzido e por alguém ligado às letras, que tenha consciência desse trabalho de tradução. A queixa de profissionais é que há problemas com a tradução. Alguns textos de Freud como Totem e Tabu são textos eminentemente literários. A gente deve recuperar este sabor literário do texto e não reduzi-lo a uma fonte de informação teórica. Lacan, que inventa uma prosa onírica e uma associação livre, foge da linearidade e oferece aos leitores dificuldades semelhante às de Finnegans Wake. O texto de Lacan não é linear, logo ele tem processos associativos em que produz o impacto, produz o choque.

${ }^{2}$ IV Encontro Nacional e III Encontro Internacional de Tradutores. ABRAPT, Fortaleza, CE, 2004. 
Ele choca deliberadamente, não procura ser claro no sentido da definição das coisas. Os textos de Lacan estão na mesma categoria de Finnegans Wake.

Podemos criar, e isto requer todo um novo comportamento, isto compromete os tradutores que estão se formando e pretendem se encaminhar para esse campo. Eles devem receber uma formação que não seja apenas técnica, mas toda uma formação psicanalítica, filosófica, literária, que pode durar uma vida toda. Veja, isto acontece com muitos cursos vigentes, inclusive a Psicologia. Os psicólogos se queixam que os cursos de psicologia são demasiadamente técnicos, os advogados se queixam que os cursos de direito são demasiadamente técnicos. Veja a importância das faculdades de direito no Brasil no século XIX: eram centros de renovação do pensamento; a geração romântica estava ligada às faculdades de direito; a geração realista de 1870 estava ligada à faculdade de direito. Este caráter, o direito perdeu. Os cursos de letras, que deveriam desempenhar esta função, estão ficando técnicos também. A atividade do tradutor está se tornando uma atividade técnica. Essa tecnicização afeta o ensino universitário, inclusive o ensino de línguas. $\mathrm{O}$ inglês é um inglês para se comunicar, quer dizer, a riqueza da literatura inglesa não aparece, e pode ser que isto também afete a língua francesa, bem como todas as outras línguas. Se eu quero ir à Franca, faço um curso de francês com esta finalidade. Temos que recuperar ou então temos que cultivar esta posição de uma formação integral, e aí deveríamos estabelecer um diálogo entre as diversas atividades. Eu não desprezo a posição técnica, mas o ensino não deve se reduzir a isso. Se, no caso, os departamentos de tradução estão preocupados com uma eficiência técnica, não cumprem com o seu dever. Você não se tornará pianista, sem agilidade, sem conhecer bem o manejo do teclado. A arte começa quando você domina a técnica. Aí você terá que andar por si mesmo. Ninguém nos ensina a inventar. Literatura é invenção na criação e na tradução. A finalidade dos cursos de tradução e das oficinas literárias é introduzir os interessados na técnica, mostrar-lhes o que outros fizeram. Vôo próprio é responsabilidade de cada um. Não pretendo me tornar um teórico da tradução, não é a minha função. Seria um charlatanismo. Estou cuidando para não ser charlatão. É preciso conhecer a teoria da literatura. O que faz Joyce, por exemplo? Mata o autor. Esta morte do autor deve me levar a uma morte do tradutor. Como é que eu posso tomar uma posição hegemônica diante de um texto de que o próprio autor se demitiu? Seria de outra forma uma infidelidade ressuscitar uma instância autoritária que foi demitida. Eu acho que todos os preceitos de tradução, que são efetivamente uma história de reflexão, são muito úteis, não para serem obedecidos, mas para serem refletidos. Não posso me dispensar da gramática de uma língua se quero me comunicar dentro desta língua. Eu não assumirei a posição de sujeito se não tenho as condições de transgredi- la. Não posso escrever em francês, em alemão, em línguas que eu domino relativamente, porque eu me sinto como execu- 
tor de regras; isso se notará imediatamente. Eu só posso criar dentro da língua portuguesa porque sei o que a língua portuguesa preceitua, porque sei como transgredir e a medida em que devo transgredir. Deve se introduzir o nosso processo de transgressão para uma posição efetiva em qualquer campo teórico. A mesma situação se dá na medicina. Como é que a medicina progride? Porque de repente alguém descobre que determinadas técnicas podem ser feitas diferentemente, até com risco de vida. Isto vale para todo campo. Deve se manter o espírito de inventividade. Temos que manter uma posição crítica frente àquilo que se faz. Não no sentido de desrespeito àquilo que se fez, mas de elevar este campo aos novos campos do saber. Se a história é móvel, se as nossas relações com a realidade são móveis, nós temos que nos preservar, nos colocando dentro desta mobilidade.

Eu estou mudando. Determinados achados, eu os consegui em cinco anos - Joyce levou 16 anos para escrever -, o que significa que seria pretensioso se eu dissesse que agora estão acabados. Enfim, a gente não pode prever a invenção; algumas soluções que eu achava boas, de repente descubro que não é bem assim, que podem ser diferentes. Eu então continuo com esses processos de insight. Evidentemente é um trabalho de reincorporação, de refazer, de repensar. Por exemplo, isto acontece na primeira palavra do romance Finnegans Wake. Na primeira tradução eu tinha perdido 'runa', presente no inglês. Na nova versão, que vai aparecer, traduzo por 'rola rio vem'. É o achado. E acontece sempre que a gente escreve, sobretudo nas situações mais relaxadas, nas situações de ócio, quando se está desobrigado - por isto quero me desobrigar. A atividade intelectual é muito diferente da situação operária, que tem um horário para entrar, um horário para sair e tarefas a serem cumpridas. Dentro deste regime nós somos absolutamente inúteis!

Donaldo Schüler donaldoschuler@yahoo.com Universidade Federal do Rio Grande do Sul

Depoimento concedido a Marie-Hélène Torres \& Mauri Furlan marie.helene.torres@gmail.com /maurizius@gmail.com Universidade Federal de Santa Catarina 